\title{
CUIDANDO, PESQUISANDO E ENSINANDO: ACERCA DE SIGNIFICADOS E IMPLICAÇÕES DA PRÁTICA DA ENFERMAGEM ${ }^{1}$
}

Vilma de Carvalho ${ }^{2}$

Carvalho V. Cuidando, pesquisando e ensinando: acerca de significados e implicações da prática da enfermagem. Rev Latinoam Enfermagem 2004 setembro-outubro; 12(5):806-15.

Artigo tem como objetivo discutir a problemática de cuidar, pesquisar e ensinar em enfermagem na prática hospitalar: traços gerais da Enfermagem Moderna - paradigma de ensino e prática; características do Sistema Nightingale. Moldagem metodológica com base na analítica de conceitos fundamentais de cuidar, pesquisar e ensinar na prática da enfermagem com implicações técnico-gnoseológicas para a prática pedagógica e da pesquisa e ilustrações em exemplos de pesquisas realizadas na área hospitalar e com repercussões para uma epistemologia da enfermagem. Ressalta-se a atitude e posições profissional para a arte. A autora invoca a necessidade de evidência, de efetividade de métodos de investigação e de confiabilidade de resultados nas atividades de cuidar, pesquisar e ensinar na enfermagem (em oncologia?). A conclusão aponta para a relevância da enfermagem como prática social e da problemática de atuação da(o) enfermeira(o) em qualquer esfera da pragmática assistencial - hospitalar e não hospitalar.

DESCRITORES: enfermagem; cuidados de enfermagem; pesquisa em enfermagem; ensino; conhecimento; prática profissional

\section{CARING, RESEARCHING AND TEACHING: MEANINGS AND IMPLICATIONS OF NURSING PRACTICE}

This article aims to discuss the problem of caring, researching and teaching in hospital nursing: general characteristics of Modern Nursing - teaching and practice paradigm; characteristics of the Nightingale System. The research methodology was based on the analysis of fundamental care, research and teaching concepts in nursing practice, involving technical and gnoseological implications for pedagogical and research practice, which are illustrated through examples of hospital research. These entail repercussions for an epistemology of nursing. We highlight professional attitudes for the state of the art. The author evokes the need for disclosure, for efficient research methods and result reliability in (oncology?) nursing care, research and teaching activities. The conclusion points towards the relevance of nursing as a social practice and the problem of nursing activities in any area of care pragmatics - whether in or outside the hospital context.

DESCRIPTORS: nursing; nursing care; nursing research; teaching; knowledge; professional practice

\section{CUIDANDO, INVESTIGANDO E ENSEÑANDO: ACERCA DE SIGNIFICADOS} E IMPLICACIONES DE LA PRÁCTICA DE LA ENFERMERÍA

La finalidad de este artículo es discutir la problemática del cuidar, investigar y enseñar en enfermería en la práctica hospitalaria: trazos generales de la Enfermería Moderna - paradigma de enseñanza y práctica; características del Sistema Nightingale. El modelo metodológico fue basado en el análisis de conceptos fundamentales cuidar, investigar y enseñar en la práctica de la enfermería con implicaciones técnico-gnoseologicas para la práctica pedagógica e investigativa e ilustraciones en ejemplos de investigaciones realizadas en el área hospitalaria y con repercusiones para una epistemología de la enfermería. Se destaca la actitud y posiciones profesionales para la arte. La autora invoca la necesidad de evidencia, de efectividad de métodos de investigación y de confiabilidad de resultados en las actividades de cuidar, investigar y enseñar en enfermería (¿en oncología?). La conclusión señala la relevancia de la enfermería como práctica social y de la problemática de actuación de los enfermeros en cualquier esfera de la pragmática asistencial - hospitalaria y no hospitalaria.

DESCRIPTORES: enfermería; atención de enfermería; investigación en enfermería; enseñanza; conocimiento; práctica profesional

\footnotetext{
${ }^{1}$ Conferência proferida na III Jornada de Enfermagem Oncológica do INCA, no dia 11.7.2002, no Rio de Janeiro-RJ; ${ }^{2}$ Enfermeira, Licenciada em Filosofia, Livre-Docente, Doutor, Professor Titular da Escola de Enfermagem Anna Nery da Universidade Federal do Rio de Janeiro, Pesquisador do CNPq, e-mail: vilma@eean.ufrj.br
} 
PONTO DE PARTIDA

$\boldsymbol{A}$ enfermagem conhecida surgiu com os enunciados nightingaleanos e consagrou-se com a fundação da Escola Nightingale de Treinamento para Enfermeiras, anexa ao Hospital Saint Thomas de Londres, em $1860^{(1)}$. Desde então, adquiriu forma e materialidade (objeto formal e material) no bojo de uma moderna concepção de enfermagem, tão consistente com um sistema de princípios básicos aos atos profissionais específicos, quanto coerente com um modelo de ensino carregado de regras pedagógicas, preceitos éticos e um estilo peculiar de cuidar. A nova concepção consolidou-se como Sistema Nightingale, posto que conjugado nos três elementos - sistema de princípios, modelo de ensino e arte de cuidar - serviu na medida à justificação da enfermagem como profissão de prática científica.

O Sistema Nightingale surgiu com mais dois aspectos significativos. Uma proposta de reforma sanitária endereçada às instituições de saúde da rede oficial, que assegurou à contribuição nightingaleana valor social e atributo de benefício à humanidade. E um projeto profissional paradigmático, de pertinência e lógica para a formalidade de preparar enfermeiras para ampliar o escopo da profissão. Enfermeiras tecnicamente treinadas para atuar em cenários variados e em nível de competência qualificada. Capazes de cuidar de pessoas enfermas e sadias, e em atenção a necessidades de recuperação e/ ou de proteção da saúde. Assim, a profissão de enfermagem adquiriu importância na preparação de pessoal, na promoção e atenção à saúde e no mundo do trabalho.

O impacto da reforma sanitária procedida na Inglaterra da era vitoriana pode ser conferida em análise autores ${ }^{(2)}$ de textos da literatura de enfermagem. Quanto à concepção de profissão moderna as novas enfermeiras estavam, de fato, preparadas para a missão de cuidar, no âmbito de sua arte. A atuação profissional podia efetuarse em cenários hospitalares e na assistência domiciliar ou comunitária. Principalmente, se aliada a programas de zonas distritais ou rurais, e com objetivos de cuidar e atender à saúde dos trabalhadores e suas famílias ${ }^{(3)}$. As atividades das enfermeiras convergiam para a prestação de cuidados específicos. Na esfera da ação, elas ensinavam higiene pessoal e ambiental, preceitos de conforto e instruções sanitárias radicadas nos princípios básicos de enfermagem. E desempenhavam, com responsabilidade, certa variedade de atos e operações peculiares, tão fundamentais para ajudar às pessoas a recuperar e/ou manter a saúde, quanto relevantes para destacar a enfermagem como prática de utilidade social. As habilidades das novas enfermeiras serviram como demarcação entre "o que se fazia antes e depois da proposta nightingaleana". Os programas de trabalho, os relatórios técnicos que elas apresentavam, eram justificados com estatísticas - requisitos de valor científico. Suas atividades realçavam competências e responsabilidades ao nível de valores éticos e do princípio pedagógico da demonstração pelo exemplo ${ }^{(3)}$.

A contribuição nightingaleana merece, ademais, o sentido de ruptura epistemológica - conceito da epistemologia bachelardiano ${ }^{(4)}$; ou seja, "o fenômeno de descontinuidade sucedendo entre o que se fazia antes e o que se passa a fazer, posteriormente, no plano do pensamento e da construção do conhecimento". Na história da enfermagem, isto é inequívoco. Mesmo não se dispondo de todas as respostas para a enfermagem na época atual, na trajetória evolutiva de mais de 140 anos, já contamos muitas aquisições, apesar dos desafios que abrangem o saber e fazer dos profissionais hoje. As novidades ou inovações científicas e tecnológicas a que chegamos, em nossa época, estão aí a exigir novas atitudes, novas condutas, novas formas de pensar e ser. Disso, as enfermeiras não escapam. Além das exigências cabíveis à prática assistencial, e dos requisitos que pesam sobre o ensino de enfermagem, agora temos os desafios da construção de conhecimentos válidos. Aos enfermeiros impõe-se posição compatível não só com a prática de cuidar e de ensinar a cuidar, mas com a prática da pesquisa e da produção científica.

O tempo é um limite, o espaço de atuação profissional a cada dia mais pressionado. Contudo, se avançamos em nível de consciência crítica e expandimos o papel profissional para incluir novas competências, não é razão para esquecermos a definição nightingaleana para uma enfermeira treinada ${ }^{(5)}$. A definição é antiga (talvez), mas merece detida reflexão, desde que o perfil profissional comporta aspectos de treinamento técnico em programas de educação continuada. A definição vale, particularmente, para a consideração dos que atuam na prática assistencial e se dedicam ao cotidiano exercício da arte de cuidar na enfermagem. É a seguinte:

"A enfermeira deve ter método, dedicação, capacidade de observação, amor ao trabalho, devoção ao 
dever (que é o serviço ao bem comum), a coragem, a frieza do soldado, a ternura da mãe, a ausência de pedantismo (que é nunca pensar que atingiu a perfeição ou que nada existe de melhor). Ela deve possuir um interesse tridimensional em seu trabalho - o interesse intelectual no caso [em apreço], o (mais elevado) interesse afetivo pelo paciente, o interesse (prático) técnico no cuidado e na cura do paciente. Ela não deve olhar os pacientes como se feitos para as enfermeiras, mas para as enfermeiras como se feitas para os pacientes".

A definição expressa o espectro da proficiência técnico-profissional da enfermeira. Obviamente, não resume tudo. Mas dela constam os traços do papel esperado da enfermeira e constam, também, aspectos do assunto que prende nossas preocupações de hoje. Há os traços distintivos - atributos intelectuais, atitudes pessoais, condutas afetivas, habilidades e interesses para o trabalho profissional e o cuidado de enfermagem. Há o imperativo do dever moral quanto ao significado dos clientes na esfera do cuidado. E, por detrás das palavras, percebe-se fatos e fenômenos do cotidiano profissional, quase que inesgotáveis, para quem deseja ou precisa se haver com a idéia do assunto designado "Cuidando, Pesquisando e Ensinando em Oncologia".

Posso estar falando do que todos já sabem. Porém, os enunciados de nightingaleanos ultrapassam a concepção e servem de ponto de partida para o enquadramento de referências para os significados da profissão de enfermeira. Dentre suas obras, duas servem de partida para uma aprendizagem profícua sobre o que seja atuação típica na área da enfermagem. Notas sobre Enfermagem - o que é e o que não é ${ }^{(6)}$, a mais célebre, expressa o apelo vocacional a uma profissão admirável. Segundo opinião reconhecida ${ }^{(7)}$, representa uma verdadeira filosofia de enfermagem. E eu acrescento, sem nenhuma dúvida, uma filosofia crítica. Note-se que a própria autora da obra explica no Prefácio:-

"As notas não devem ser entendidas como regras de pensamento pelo qual as enfermeiras possam ensinar, a si próprias, a serem enfermeiras, tampouco devem servir de manual para ensinar as enfermeiras a cuidar".

Entendo que a insigne talvez quisesse preservar seu livro para uso não só das enfermeiras, mas de todos que pudessem cuidar de pessoas, em nome da enfermagem. Quanto à importância que a autora atribui à arte de enfermagem, a obra fala por si, na interpretação e argumentos para justificar tal "arte" no plano de uma prática científica, apoiada em princípios básicos e proposições de valor teórico para a atuação profissional. As Notas ressaltam, ainda, aspectos éticos e requisitos adequados a atitudes e comportamentos esperados dos que assistem e ajudam aos que necessitam de cuidados. Se não indica tudo de instruções e cuidados à saúde humana, no todo e nas partes, o livro trata "do que convém e do que não convém às enfermeiras", no âmbito da arte de cuidar.

Da segunda obra, Notas sobre Hospitais, escrita antes da fundação da Escola Nightingale, a mesma crítica refere $^{(7)}$ "o que mais causa espanto é a sentença provocativa da autora ao iniciar seu livro":

"Parecerá, talvez, um estranho princípio enunciar que o primeiro requisito de um hospital consiste no dever de não prejudicar o paciente".

(...) E ela acrescenta, depois, (...)

"O cuidado do enfermo é o principal objeto dos hospitais. O cuidado de suas almas é o grande ministério dos clérigos dos hospitais. O cuidado de seus corpos é do dever das enfermeiras hospitalares".

Essas proposições abarcam idéias essenciais e conceitos de substancialidade e de causalidade, que, na teoria do conhecimento ${ }^{(8)}$, servem para aliar ou fundamentar o pensamento quanto aos termos do objeto de estudo. Interessa tanto o que se consubstancia na esfera do profissional, quanto o que diz respeito aos significados na esfera do que se busca como real objetivado. No caso da enfermagem, independentemente seja entendida como concepção teórica ou como prática substantiva, a idéia faz sentido nas palavras cuidando, pesquisando, ensinando. A meu ver, as sentenças referidas servem à interpretação e à justificação do cuidado ao cliente como objeto da enfermagem, no âmbito da prática de cuidar, de pesquisar e de ensinar.

Embora sem detalhar mais, as duas obras contribuem para a compreensão da Enfermagem Moderna. Servem de base explicativa para a profissãoe, no conjunto, valem por uma verdadeira teoria axiomática para o que seja cuidar de enfermos e de sãos ${ }^{(9)}$. Penso que os enunciados ou explicações merecem reflexão e servem para orientar a crítica do pensamento e da atuação profissional. É só uma idéia, mas penso que podem servir, também, para conjeturas acerca de estudos e pesquisas para o conhecimento na enfermagem, seja entendida como arte de cuidar ou de ensinar a cuidar.

Os colegas enfermeiros esperam talvez ampliar o 
entendimento do assunto circunscrito nas palavras cuidando, pesquisando e ensinando [na enfermagem]. Não posso falar como especializada na área de oncologia. Não é sem razão que alguns autores afirmam ${ }^{(10)}$ que "um dos indicadores mais seguros da capacidade de conhecimento de alguém é a certeza de que, quanto mais sabe, mais se convence de que pouco sabe". É o meu caso. Contudo, pude adquirir experiência assistencial no velho Hospital Escola São Francisco de Assis (HESFA/UFRJ), onde pude aprender técnicas de cuidar e manejo de métodos de ensinarna enfermagem. Como Chefe de Enfermaria (anos 50 e 60), participei de tratamentos de pacientes com câncer e aprendi, também, de tratamentos quimioterápicos que se iniciavam na ocasião. Sei que toda explicação deve condizer a uma teoria, e se não condiz deve, pelo menos, convir ao real da experiência. Se não dispondo de conhecimento aprofundado na área, que a experiência seja colocada no interesse da enfermagem. Mas fique assentado, o que mais tenho aprendido é a busca do conhecimento, não a certeza de que tudo sei. Sobre o assunto em pauta, só posso falar acerca de significados e implicações para a prática da enfermagem.

\section{SOBRE CUIDAR E ENSINAR A CUIDAR}

Então, já de saída a pergunta que se coloca é:Até que ponto a experiência vivida pode me valer de âncora para ajudar no entendimento do assunto circunscrito nas palavras cuidando, pesquisando e ensinando [na enfermagem]?

Como enfermeira e professora, adquiri experiência profissional, na veneranda Escola de Enfermagem Anna Nery (EEAN/UFRJ), onde aprendi idéias primordiais de relevar a enfermagem como arte de cuidar e de ensinar a cuidar. Desde a graduação, tais idéias impulsionaram-me à curiosidade intelectual e aos intentos de buscar o conhecimento. Também aprendi, dentre outros, princípios fundamentais, como os seguintes:

"O quanto mais e melhor aprende-se a cuidar é cuidando. Na enfermagem, o cuidado do paciente é central, é a suposição primeira e última a justificar a presença da enfermeira, no âmbito da arte de enfermagem".

"A prática de cuidar, na assistência à saúde, em qualquer instituição ou no domicílio, é demarcada pelos cuidados de enfermagem. A enfermeira não pode por lei e nem por dever moral abrir mão de sua responsabilidade de cuidar e de ensinar a cuidar".

"As necessidades dos clientes é que determinam os cuidados de enfermagem de que carecem".

Apesar dos esquemas administrativos reguladores da distribuição dos clientes por enfermidades, ou especialidades médicas, como enfermeira adotei esses três princípios como regras para nortear a posição de enfermeira na prática assistencial e na prática pedagógica. Sei que as mudanças e as inovações tecnológicas revolucionaram a prática profissional na área da saúde e que, agora, tudo acontece diferente. Percebo que as especialidades multiplicam-se a todo instante, fragmentando a área da saúde e os esquemas de trabalho que abarcam a prestação de cuidados de enfermagem. Pior de tudo, nulificam o apelo vocacional da missão da enfermeira como artífice principal de sua arte - arte de enfermeira ${ }^{(11)}$. Como professora, só entendo o processo de ensinar no plano pedagógico do engajamento com as situações da prática assistencial. Isto implica que, na estrutura formal do preparo de profissionais competentes para a arte de cuidar, "aprende-se enfermagem" - cuidando, e "ensina-se enfermagem" - ensinando a cuidar. Tenho afirmado isso em outras ocasiões. As minhas ex-alunas, hoje diletas colegas, líderes na profissão, não me deixam em dúvida.

Assim, a presença da enfermeira, no âmbito de atos e operações de cuidar, é o mais importante aspecto para aprender-se o significado da enfermagem como prática $v_{i v a}{ }^{(12)}$. Tão importante quanto o instrumental filosófico que abrange a profissão como prática total. Minha profissão de fé, - de profissão de enfermeira e professora -, condiz com a idéia de que a enfermagem cristaliza-se no encontro da enfermeira com os clientes. Encontro em que a pedra de toque é o cuidado de enfermagem. Nesse encontro, entende-se o corpo da enfermeira como instrumento do cuidado $^{(13)}$. O corpo da enfermeira justifica e releva o cuidado prestado. Sem a presentificação do corpo da enfermeira, algo se perde na essência do cuidado e na natureza da enfermagem. Para os que aprendem a cuidar e a ensinar a cuidar, a presença (ou posição) da enfermeira, na esfera do cuidado, faz a diferença entre "o que é e o que não é" na enfermagem. Pode parecer idealização utópica, quando sabemos que a pirâmide representativa da força de trabalho na enfermagem só estabelece o ápice para ilustrar o esforço dos enfermeiros. Contudo, a responsabilidade legal e social pelas ações de 
enfermagem recai sobre o papel da enfermeira, donde imprescindível sua presença no cuidado aos clientes. Ou seja, as ações de cuidar e de ajudar às pessoas e aos grupos humanos em situações de riscos, de incapacidades, de falências, de condições precárias para prover o cuidado à saúde, asseguram significado $e$ propósito à enfermagem, e assim ao campo de ação dos enfermeiros.

Não que o arcabouço teórico da enfermagem tenha menos valor. Mas de tão importante a presença da enfermeira no âmbito da prática de cuidar e de ensinar a cuidar que, na EEAN, deslocamos a ênfase curricular na graduação para destacar a posição da enfermeira, no processo assistencial e plano total da prática. Tenha-se em consideração o marco conceitual do atual Currículo de Graduação(14), para o qual estabelecemos, explicitamente, a proposição seguinte:

"A ENFERMEIRA atua como fulcro de um PROCESSO do qual emerge a prática total da ENFERMAGEM entendida como a CIÊNCIA e a ARTE DE AJUDAR a indivíduos, grupos e comunidades, em SITUAÇÕES nas quais não estejam capacitados a prover - AUTO-CUIDADO para alcançar seu nível ótimo de SAÚDE".

Não dá para explicar os elementos e novos conceitos (palavras maiúsculas). Mas entendemos que cabe à posição profissional um perfil diferenciado de competências que ampliam a atuação da enfermeira em termos de responsabilidades técnicas, políticas e sociais. A arte de cuidar e de ensinar a cuidar estão preservadas, mas tornaram-se imprescindíveis a pesquisa e os diagnósticos de situações dos clientes. A palavra "fulcro" dá novo sentido à atuação da enfermeira no âmbito da profissão. Em sentido específico, a enfermeira atua como na idéia de alavanca que equilibra e desencadeia o movimento processual da enfermagem - ciência e arte de ajudar às pessoas, aos grupos e comunidades na provisão de cuidados à saúde. Na prática, requer consciência crítica, posicionamento político, liberdade de pensamento, e logística para empreender mudanças na área profissional.

No final dos anos 70, a proposição parecia visionária e demandou muita discussão de enfermeiros assistenciais e de ensino. Com a falência do sistema de acesso à saúde, os novos conceitos a demarcar o ensino de graduação parecem justificar melhor a importância da posição da enfermeira. Aliás, as atuais circunstâncias e condições da arte de cuidar e de ensinar a cuidar, estão a exigir urgente reconsideração. Todos sabem das dificuldades do processo ensino-aprendizagem que, na prática, parece à deriva ou à mercê de soluções emergentes. Haja vista à falta de pessoal, de cenários apropriados aos estágios, a insuficiência de recursos, a precariedade nos acordos interinstitucionais e nos entendimentos de política educacional. Neste aspecto, os enfermeiros - assistenciais e de ensino - precisam discutir e pesquisar situações-problemas de seu próprio campo de atuação. As implicações teóricas e práticas parecem convulsionar a prestação de cuidados. Pior de tudo, há os riscos da expropriação da presença da enfermeira na esfera específica do cuidado de enfermagem.

Assim, por detrás do marco conceitual, sobressaise a idéia de mais autonomia para a posição da enfermeira. Tenha-se em mente os desafios da prática profissional quanto à necessidade de ajudar pessoas e grupos humanos a aprender a cuidar de si próprios. Neste particular, é imprescindível a aprendizagem de novos princípios - de participação política, de economia e de jurisprudência - pertinentes aos direitos à saúde. Os estudantes de enfermagem precisam ser esclarecidos quanto à responsabilidade social que herdam, principalmente em relação aos direitos dos clientes e aos significados da posição da enfermeira no mundo de hoje.

\section{SOBRE PESQUISAR E ENSINAR A PESQUISAR}

Com as mudanças educacionais sucedidas na década de 70, e em razão dos avanços da enfermagem como projeto acadêmico, alguns enfermeiros se encontram reconhecidos como pesquisadores. Mas ainda há muito que aprender. Daí as dificuldades para discutir a palavra pesquisando em enfermagem. Muito do já acumulado devese às imposições e conseqüências da Pós-Graduação stricto sensu, no mundo inteiro. Não obstante, no Brasil, a maioria dos enfermeiros está só começando a cadenciar os passos com a pesquisa científica. Nas instituições de ensino, a duras penas estamos pesquisando e ensinando a pesquisar. Mesmo contando já uns trinta anos de experiência, os resultados alcançados parecem não condizer com evidências para o conhecimento construído. Com isso, os projetos da enfermagem sofrem de restrições impostas pelos organismos ou agências de fomento e amparo à pesquisa.

Todavia, nessa época, já se discutia o princípio 
da investigação e a busca de respostas para a observação sistematizada na enfermagem ${ }^{(15)}$. Discutia-se métodos de pesquisa e sua aplicabilidade na elaboração de dissertações e teses. Mas pouco se sabia de onde partir, ou como prosseguir para efetivar as pesquisas. Muito foi aprendido com os estudantes, no ato pedagógico de orientá-los. De minha ótica, percebi cedo que os problemas a pesquisar e a ensinar a pesquisar ou são emergentes da prática de cuidar e de ensinar a cuidar, ou se referem ao abrangente da totalidade da prática da enfermagem. Portanto, nem os conceitos e definições são intocáveis. Tudo merece questionamento, discussão e análise, bem como a submissão às regras da demonstração e das provas.

Com efeito, aprendi orientando pesquisas e ensinando a pesquisar. Penso que algumas proposições merecem destaque para reflexões e conjeturas dos que se engajam com as pesquisas. Mormente, pelo fato de que a enfermagem não se conforma, inteiramente, aos traços distintivos da ciência (re)conhecida ${ }^{(16)}$. Por exemplo, as seguintes:

- As concepções teóricas ou filosóficas servem para enquadrar os tópicos da enfermagem, comportem ou não soluções; mais importante, porém, é assegurar os princípios de substancialidade e de causalidade para o conhecimento que se persegue.

- As teorias apoiadas em suposições, conjeturas, hipótese, continuam sendo discutidas, verificadas, reformuladas, ou refutadas; o mais importante é saber como conduzir, na enfermagem, a preferência em relação a umas em vez de outras.

- Todos os métodos científicos e/ou filosóficos são úteis, desde que aplicáveis às pesquisas de enfermagem; o mais importante é perseguir a busca de conhecimento para a profissão.

- Os métodos preferíveis na investigação devem convir ao esforço de elucidar situações humanas e minúcias que conferem significado à vida; o mais importante é a participação ou engajamento do pesquisador aos termos da experiência objetiva, da história e do pensamento sobre enfermagem.

- Todas as circunstâncias que abrangem enfermeiras e clientes, na esfera de cuidar e ensinar a cuidar, servem de objeto de pesquisa na busca do conhecimento; o mais importante é focalizar as situações em que as pessoas nascem, vivem e morrem.

- Explorar o já conhecido pode ter pouco valor para a pesquisa de enfermagem; o mais importante é adequar a tonalidade qualitativa das respostas aos quantitativos que possam sinalizar no sentido das evidências.

- A atuação profissional, nas instituições reguladas por normas inflexíveis servem às pesquisas na enfermagem; o mais importante, porém, é o que concerne à formação da consciência crítica, à educação para a mudança e à preparação das pessoas para o futuro, incluídos todos os envolvidos.

- Palavras como absoluto, perfeito, imutável, e outras semelhantes não servem ao vocabulário para nortear as questões da enfermagem; o mais importante é atender aos termos do conceito de enfermagem - ciência e arte, incluída a sua história.

Essas proposições $^{(17)}$ não esgotam os requisitos adequados às pesquisas na enfermagem. Mas podem servir para iluminar as idéias dos que se aventuram pelos caminhos da pesquisa na enfermagem. Assim, em vista das expectativas, penso não ser demais colocar alguns exemplos de pesquisas realizadas na Graduação e PósGraduação de Enfermagem - Mestrado e Doutorado. Os exemplos de alguns autores de enfermagem servem tanto para ilustrar a prática de pesquisar e de ensinar a pesquisar, como servem também aos questionamentos sobre a arte de cuidar na enfermagem. E penso que podem ajudar aos enfermeiros - assistenciais e de ensino - a ponderar melhor as situações onde os problemas emergem. Vejamos, então:

- Banhando uma Enfermeira: os desafios de olhar e tocar o Corpo $\mathrm{Nu}^{(18)}$

Pesquisa qualitativa de dados obtidos na "experiência de banhar". Participaram 24 enfermeiras (22 mestrandas e 02 professoras). Discutiu-se o filme "O Golpe do Destino" para saber de percepções das enfermeiras quando sentem, olham e tocam o corpo nu. A metodologia incluiu o registro de cenas de cuidar e banhar e momentos de reações, expressões e gestos, durante a atividade. Categorizou-se as informações, donde surgiram 03 núcleos: 1.- Banho no Leito: congelando o olhar de corpos sentados - as observadoras das observadas; 2.- Banho no Leito: congelando os movimentos dos corpos em pé as que efetuam o banho; e 3.- Esquentando o corpo com o Banho no Leito:- a que tomou o banho. Os dados obtidos indicam necessidade de compreender gestos e expressões na atividade; a idéia do Banho no Leito condiz ao "ritual", sendo a cama o "altar de celebração"; mesmo sem uniformes e no plano pedagógico, as respostas das 
enfermeiras conferem com o imaginário coletivo, com lembrança dos próprios corpos e atributos da ética cristã, mesclados com reações de medo, ansiedade $e$ expectativa.

- (Re)lembrando Elvira De Felice: os gestos e as falas das Enfermeiras sobre o Banho no Leito - técnica ou tecnologia de enfermagem $?^{(19)}$

Pesquisa quanti-qualitativa de Banho no Leito para objetivar expressões verbais e não-verbais, durante a atividade de banhar e ser banhada - designada "cena de reflexão". Participaram 32 Enfermeiras (mestrandas). As informações incluíram - registro de falas, gestos, expressões, e comentários durante a atividade. Os resultados ensejaram 02 núcleos de representações: 1. O Corpo que toca e fala; e 2. O Corpo que toca e cala. A abordagem teórico-metodológica incluiu a Multireferencialidade, a Subjetividade e a Psicossociologia. Os resultados apontaram dificuldades das enfermeiras em relação a toque e corpo, além de outras aliadas a emoções, subjetividade, estética, e sensualidade.

- Indicadores de Cuidados para o Corpo que Procria: Ações de Enfermagem no pré-trans e pós-parto - uma contribuição à prática da enfermagem obstétrica ${ }^{(20)}$

Pesquisa qualitativa com base em dinâmicas designadas "cenas de produção estética". Participaram 28 Enfermeiras (assistenciais e de ensino) para responder à questão: $O$ que se produz sobre o corpo em trabalho de parto, quando se cuida no pré-trans e pós-parto?Objetivouse identificar e discutir ações profissionais nos momentos em que o corpo da mulher dá origem a outra vida. Os resultados serviram a 03 categorias de ações aliadas à prática do cuidado: 1.- O Cuidado do Corpo em trabalho de parto - a (in)devida invasão e a violência velada (28 respostas); 2.- O (des)cuidado do Corpo que (ex)pulsa outro corpo - a invasão e a violência mostrada (19 respostas); e 3.- O (des)cuidado do Corpo vazio: "cansaço e solidão" - a violência do abandono (23 respostas). As categorias apontam cuidados (in)devidos à cliente indicativos do dever profissional de evitar violência sobre o corpo da mulher em processo de parto.

- Dama de Negro, Dama de Branco: Mulheres disputando a vida com a morte - o Cuidado [de enfermagem] na fronteira de combate ${ }^{(21)}$

Estudo (pesquisa) sobre a experiência de cuidar baseada em registros de "diário de campo", durante 50 dias. Participaram Enfermeiras (assistenciais e de ensino) e estudantes de enfermagem no cuidado de 01 cliente com prognóstico médico de "morte como saída", e prognóstico de enfermagem de "vida como possível e viável". Ações de cuidar incluíram o toque - sensibilidade e sensualidade - para manter a integridade física e mental, os estímulos corporais, visuais e auditivos, e a disponibilidade da enfermagem para "querer cuidar", "querer pensar", "querer julgar" [a efetividade] do trabalho [de enfermagem] - e "saber intervir" com capacidade para compreender, para amar, para acreditar, e para intuir, até quanto à implementação da terapêutica médica. Os resultados apontaram a permanente presença da enfermagem como potencial responsável pela manutenção da vida do cliente.

São exemplos de resumos de pesquisas apresentadas nos eventos de enfermagem. Não dizem tudo, mas servem à idéia da aplicabilidade de métodos de buscar algumas respostas para o conhecimento, independentemente dos cenários práticos da atuação profissional. Valem pelas tentativas de alcançar núcleos significativos para uma epistemologia da enfermagem ${ }^{(22)}$. E como não há como escapar de realizar pesquisas, mesmo se os resultados são parcos, servem para aprender a pesquisar pesquisando e, também, para ensinar a cuidar pesquisando. Isto pode relevar experiências para o conhecimento objetivo, além de ressaltar a pesquisa como requisito de qualidade acadêmica. Não é fácil explicar. Mas prioridades e produção intelectual da enfermagem carecem de justificação pela pesquisa científica, bem como de resultados efetivos (evidências?) para o saber e fazer, na prática profissional. Os pleitos da enfermagem dependem de aprovação controlada por organismos nacionais e internacionais. Diante de normas de agências de fomento e de exigências de avaliação educacional, não há outra saída salvo os caminhos da investigação científica para preencher os vazios do conhecimento de enfermagem.

\section{PONTO DE CHEGADA}

A conta do exposto, todos os enfermeiros têm que se haver com os significados e implicações da Enfermagem - ciência e arte. Nas áreas de atuação profissional, todos precisam e devem pesquisar. Não apenas em projetos de participação multidisciplinar ou interdisciplinar. Mais importante são os objetivos e os interesses da profissão, nas circunstâncias das palavras 
cuidando, pesquisando, ensinando. As respostas ou servirão à pertinência conceitual, ou à conveniência legal e legítima da profissão, e devem ser buscadas nas situações da prática. Pertinência da prática de cuidar e de ensinar a cuidar. Conveniência, pois, de pesquisar e de ensinar a pesquisar. É preciso consolidar, impreterivelmente, o conhecimento de enfermagem. As teorias sociais são muito importantes. Mas respostas para conceitos específicos, atos e operações peculiares precisam de conferência com o conhecimento objetivo ${ }^{(23)}$, ou pelo menos de compatibilidade com o conhecimento confiável(24) ${ }^{(2)}$ precisam de conferência com a pesquisa na literatura de enfermagem. $O$ apego a relatos de experiências, o desapreço a critérios de observação, a falta de regras de controle, a desatenção a princípios metodológicos, com certeza prejudicarão os julgamentos dos enfermeiros. E poderão desmerecer o quilate do pensar e saber profissional, com demérito para as pesquisas adequadas ao conhecimento e à prática dos enfermeiros.

Dificuldades na pesquisa e desafios acadêmicos não são de menos valia. Não numa época em que o (re)conhecimento científico é indiscutível para os avanços da profissão, ou melhor dizer para assegurar o valor do pensamento sobre enfermagem. Da ótica do que seja pesquisando na enfermagem, percebo que todos, ou quase todos, ainda precisam se afirmar pela enfermagem, não só para a busca de mais conhecimento para enriquecer a especificidade do pensamento profissional. Mas para esclarecer as dimensões do papel social e a relevância da posição dos enfermeiros no campo de sua prática. Minhas colocações não são definitivas. Porém, nos cenários da prática substantiva, nas mais das vezes, a atuação da enfermeira deixa a desejar. Não apenas quanto ao pensamento sobre enfermagem, mas pelo que padece o estilo de cuidar e de ensinar a cuidar. Os atos e operações nas atividades processados nem sempre se justificam. Razão (talvez) da produção científica não apontar na direção das evidências. Não adianta confiar só no valor da pragmática assistencial. Em se tratando de (re)considerar e defender o conhecimento profissional, o que vale mesmo é a evidência científica, ou pelo menos o reconhecimento da confiabilidade dos resultados atingidos.

Assim, as pesquisas precisam apoiar as proposições dos enfermeiros em relação ao que se circunscreve nas palavras cuidando, pesquisando, ensinando. Ademais, a produção e a divulgação científica tornaram-se, também, imperativos da prática assistencial, em razão dos mesmos requisitos que conferem significado à prática acadêmica. Significado crucial para o perfil profissional dos enfermeiros, com conseqüências que atingem tanto a atuação no cotidiano de cuidar dos clientes, quanto no plano acadêmico da educação superior.

$\mathrm{Na}$ verdade, temos leis e regulamentos (até em demasia) para a defesa da posição profissional e para justificar atos e operações peculiares. Contudo, a exigência indiscutível é a de que precisamos, na enfermagem, falar e argumentar com base nos requisitos da ciência. Para isso, já dispomos de armamentário intelectual e legal como recursos balizadores de argumentos convincentes para a defesa da posição profissional. Não vejo, pois, a falta de espaço para o pensamento ousado, adequado à crítica e à pesquisa.

Mas convém considerar que, por triviais que pareçam as questões norteadoras, os fatores intervenientes, os problemas a pesquisar devem ser entendidos como reais, concretos, na objetividade da prática de cuidar e de ensinar a cuidar na enfermagem. A escala de mudanças, a transição das novidades, a (im)permanência das coisas suscitam outros problemas a pesquisar. Problemas das situações em que vivemos e trabalhamos. Problemas que se opõem às nossas crenças, alteram as condições que nos rodeiam e (des)organizam nosso modo de pensar e ser. Problemas aliados a valores ético-profissionais da atuação da enfermeira em nossos dias ${ }^{(25)}$. Não se pode esquecer que as situações da enfermagem são parte da trama da vida e dos acontecimentos do mundo. São situações onde as pessoas nascem, vivem e morrem. Situações que são parte integrante dos planos da saúde coletiva, e do mundo do trabalho de muitos que partilham da mesma área, dos interesses e desafios da posição profissional da enfermeira.

Mas não se pode esquecer que os problemas mais condizentes com as pesquisas na enfermagem são os mesmos que interferem na esfera do cuidado aos clientes. Esses, mais do que outros têm a ver com a inerência dos significados de cuidar, de pesquisar e de ensinar, no plano do conhecimento de enfermagem. Na prática, tais problemas precisam ultrapassar os interesses individuais dos pesquisadores, para compreender o mundo real das pessoas e de suas famílias. Na totalidade da prática da enfermagem ${ }^{(26)}$, esses problemas são pertinentes, também, aos sujeitos que integram as equipes de trabalho na área da saúde. Tampouco devemos esquecer que tais 
problemas se encontram aliados às diretrizes e aos esquemas de pensamentos que herdamos dos que viveram e pensaram antes de nós. E ainda precisamos creditar valor ao pensamento da pós-modernidade ${ }^{(27)}$, cuja influência na atuação profissional da enfermeira já se faz sentir e, certamente, se projeta para o futuro. Queiramos ou não, todos nós - enfermeiros assistenciais e de ensino - participamos das reações às mudanças de nosso tempo, e das mesmas pressões ao estilo de pensar, de trabalhar e de viver os desafios de uma posição profissional comum.

Nesse sentido, cumpre-me enfatizar a enfermagem como prática viva. Sendo o cuidado a demarcação - substância e causa - das ações profissionais na prática. Prática que adquire vida (por assim

\section{REFERÊNCIAS BIBLIOGRÁFICAS}

1. Seymer LR. Florence Nightingale - pioneira da enfermagem e precursora da emancipação feminina. São Paulo (SP): Melhoramentos.

2. Loyola Miranda CM. O Risco e o Bordado - um estudo sobre formação de identidade profissional. [Tese]. Rio de Janeiro: Escola de Enfermagem Anna Nery/UFRJ; 1996.

3. Carvalho V. A Enfermagem de Saúde Pública como Prática Social - um ponto de vista crítico sobre a formação da enfermeira em nível de graduação. Escola Anna Nery- Rev Enfermagem julho 1997; (número especial).

4. Bachelard G. A Formação do Espírito Científico: contribuição para uma psicanálise do conhecimento. Rio de Janeiro (RJ): Contraponto; 1996.

5. Nightingale F. Sick-Nursing and Health Nursing. (Paper Woman's Mission (read at Chicago 1893) In: Sir Edward Cook. The Life of Florence Nightingale - 1913. v. 2 (Appendix with A List of The Wrightings by Florence Nightingale) (Tradução livre da definição de enfermeira treinada de Vilma de Carvalho). 6. Nightingale F. Notas sobre Enfermagem: o que é e o que não é. São Paulo (SP): Cortez/ABEn-CEPEn; 1989.

7. Seymer LR. The Wrightings of Florence Nightingale. An Oration delivered before The Ninth Congress of The International Council of Nurses. Atlantic City; 1947.

8. Hessen J. Teoria do Conhecimento. Coimbra (PT): Armênio Amado Editora; 1987.

9. Carvalho V. Acerca de las Bases Teóricas, Filosóficas, Epistemológicas de la Investigación Científica - El caso de la Enfermería. Conferência apresentada no Curso Internacional de Investigación en Salud. Um Programa Científico do Colégio Nacional de Enfermeiros do Peru, Lima; Junho 2001.

10. Demo P. Teoria - Porque?. Anais do I Simpósio Brasileiro de Enfermagem. Florianópolis (SC): Editora da UFSC; 1985. 11. Parsons E. A Enfermagem Moderna no Brasil. Escola Anna Nery- Rev Enfermagem julho 1997; (número especial).

12. Carvalho V. Dimensões do saber-fazer do Enfermeiro que fundamentam o conteúdo do Currículo de Graduação. Anais do Encontro Nacional de Escolas de Enfermagem-ENESC. São Paulo (SP): Frontis Editorial/UNIFESP; 1996.

13. Figueiredo NMA de, Carvalho V. O Corpo da Enfermeira como Instrumento do Cuidado. [Tese]. Rio de Janeiro (RJ): Revinter; 1999. dizer) no encontro da enfermeira com seus clientes. Prática que se cristaliza no envolvimento com outros engajados na esfera dos cuidados aos clientes, a qual, para a enfermeira e os de sua equipe, a esfera objetiva de atos e operações de cuidar na enfermagem. Esfera de capital importância em todas as dimensões da atuação profissional. Assim como penso, mesmo na prática de ensinar e na de pesquisar, a esfera do cuidado de enfermagem tem prioridade diante das outras esferas que servem às formalidades da atuação profissional. Sem dúvida, o cuidado de enfermagem incide na inerência do significado de questões epistemológicas da atuação da enfermeira e dos propósitos de sua arte, no plano da enfermagem como prática social(3).

14. Carvalho V, Castro IB, Paixão S de S. Um Projeto de Mudança Curricular no Ensino de Enfermagem em nível de Graduação que favorece aos propósitos emergentes da Prática Profissional. Anais do $30^{\circ}$ Congresso Brasileiro de Enfermagem; 1978. Belém; PA. Brasília (DF): ABEn Nacional; 1978.

15. Carvalho V. Dos Princípios e Proposições da Observação Sistematizada na Enfermagem. Rev Bras Enfermagem 1971; 24(5).

16. Carvalho V. Sobre Construtos Epistemológicos nas Ciências - uma contribuição para a enfermagem. Anais do $11^{\circ}$ Seminário Nacional de Pesquisa em Enfermagem; Maio 1978. Belém; PA. Belém: ABEn Nacional; 2001.

17. Carvalho V. Acerca da Investigação de Problemas Assistenciais de Enfermagem Hospitalar - conjeturas e proposições. Programa Científico do 27 Congresso Brasileiro de Enfermagem; 1975. Salvador: ABEn-BA; 1975.

18. Figueiredo $\mathrm{N}$, et al. Banhando uma Enfermeira: desafios de olhar e tocar o corpo nu. In: 49 Congresso Brasileiro de Enfermagem; 1997. Belo Horizonte: ABEn-MG; 1997.

19. Figueiredo $\mathrm{N}$, et al. (Re)lembrando Elvira De Felice: os gestos das Enfermeiras sobre o Banho no Leito - técnica ou tecnologia de enfermagem? In: 49ํㅡㄹ Congresso Brasileiro de Enfermagem; 1997. Belo Horizonte: ABEn-MG; 1997.

20. Figueiredo $\mathrm{N}$, et al. Indicadores de Cuidados para o Corpo que Procria: Ações de Enfermagem no Pré-trans e Pós-parto - uma contribuição para a prática de Enfermagem Obstétrica. In: 6 Congresso Brasileiro de Saúde Coletiva; 200028 ago.1 set. Salvador; BA. Rio de Janeiro: ABRASCO; 2000.

21. Figueiredo $\mathrm{N}$, et al. Dama de Negro, Dama de Branco: Mulheres disputando a vida com a morte - o cuidado na fronteira de combate. In: 3 ํ Encontro Nacional de Enfermeiros de Hospitais de Ensino; 1995. Campinas; 1995.

22. Carvalho V. Tendências da Pesquisa na Enfermagem aspectos epistemológicos e outras implicações. Anais do $2^{\circ}$ Forum Mineiro de Enfermagem "Pesquisar para Caminhar". Uberlândia (MG): UFU; set 2000.

23. Popper Karl. Conhecimento Objetivo. Belo Horizonte (MG): Itatiaia/EDUSP; 1975.

24. Ziman J. O Conhecimento Confiável - uma exploração dos fundamentos para a crença na ciência. Campinas (SP): Papirus; 1996.

25. Carvalho V. Dos Valores Ético-Profissionais da Enfermagem Contemporânea - considerações filosóficas. Escola Anna Nery - Rev Enfermagem set 1997;1(1). 
26. Carvalho V. A Relação de Ajuda e a Totalidade da Prática da Enfermagem. Anais do $32^{\circ}$ Congresso Brasileiro de Enfermagem; 1980. Brasília: ABEn Nacional; 1980.

27. Santos B de S. Introdução a uma Ciência Pós-Moderna.

Rio de Janeiro (RJ): Graal; 1989. 